\title{
Article \\ Fresh Properties and Sulfuric Acid Resistance of Sustainable Mortar Using Alkali-Activated GGBS/Fly Ash Binder
}

\author{
Osama Ahmed Mohamed *(D) and Rania Al Khattab \\ College of Engineering, Abu Dhabi University, Abu Dhabi P.O. Box 59911, United Arab Emirates; \\ raniaW178@yahoo.com \\ * Correspondence: osama.mohamed@adu.ac.ae
}

check for updates

Citation: Mohamed, O.A.; Al Khattab, R. Fresh Properties and Sulfuric Acid Resistance of Sustainable Mortar Using Alkali-Activated GGBS/Fly Ash Binder. Polymers 2022, 14, 591. https://doi.org/10.3390/ polym14030591

Academic Editors: Wei-Hao Lee, Yung-Ching Ding and Kae-Long Lin

Received: 8 January 2022

Accepted: 29 January 2022

Published: 1 February 2022

Publisher's Note: MDPI stays neutral with regard to jurisdictional claims in published maps and institutional affiliations.

Copyright: (c) 2022 by the authors. Licensee MDPI, Basel, Switzerland. This article is an open access article distributed under the terms and conditions of the Creative Commons Attribution (CC BY) license (https:// creativecommons.org/licenses/by/ $4.0 /)$.

\begin{abstract}
In this study, sorptivity, setting time, resistance to sulfuric acid, and compressive strength of mortars that use alkali-activated GGBS and fly ash as binders, were evaluated experimentally. The activation of binders, was achieved at room temperature of $22 \pm 2{ }^{\circ} \mathrm{C}$ using combinations of sodium silicates $\left(\mathrm{Na}_{2} \mathrm{SiO}_{3}\right)$ and sodium hydroxide $(\mathrm{NaOH})$ solutions in ratios of $1.5,2.0$, and 2.5. The parameters considered in terms of their effects on fresh and hardened properties include: $\mathrm{NaOH}$ molarity, activator ratio $\mathrm{Na}_{2} \mathrm{SiO}_{3} / \mathrm{NaOH}$, mortar sample age, and relative amount of GGBS/fly ash in binder combination. Sorptivity, change in mass, and compressive strength were determined for mortar samples that were submerged in 10\% sulfuric acid solution for 7 days, 28 days, and 90 days. The binder for mortar samples tested at each of the specified ages consisted of 100\% GGBS (G100), $75 \%$ GGBS+25\% fly ash (G75F25), or 50\% GGBS + 50\% fly ash (G50F50). The binder was activated using $\mathrm{Na}_{2} \mathrm{SiO}_{3}$ solution, combined with $10 \mathrm{M}, 12 \mathrm{M}, 14 \mathrm{M}$, or $16 \mathrm{M} \mathrm{NaOH}$ solution. It was found that sorptivity decreases with increase in curing age, for all activator ratios, concentrations, and relative amounts of GGBS/fly ash. Binder consisting of 75\%GGBS + 25\% fly ash with $\mathrm{NaOH}$ concentration of $12 \mathrm{M}$ had the lowest sorptivity. Exposure of alkali-activated GGBS/fly ash mortar samples to sulfate attack did not cause loss in mass nor visible signs of damage/deterioration. All binder combinations experienced increase in compressive strength after curing in $10 \%$ sufluric acid solution, with the optimum G75F25 mix achieving a 28-day strength of $80.53 \mathrm{MPa}$ when $\mathrm{NaOH}$ molarity is $10 \mathrm{M}$, which increased to $91.06 \mathrm{MPa}$ after 90 days. Variation in concentration of $\mathrm{NaOH}$ didn't cause significant change in the magnitudes of 28-day or 90-day compressive strengths of G50F50. However, despite slow dissolution of fly ash and immersion in 10\% sulfuric acid solution, G50F50 developed 28-day compressive strength of 56.23 MPa and 90-day compressive of $86.73 \mathrm{MPa}$, which qualifies G50F50 as high strength mortar for practical purposes.
\end{abstract}

Keywords: alkali-activated fly ash and slag; concrete durability; sorptivity; alkaline activator ratio; decrease of $\mathrm{CO}_{2}$ emissions; sulphuric acid; compressive strength

\section{Introduction}

Typical design considerations for suitability of concrete in a typical application include workability/flowability, setting time, durability, and compressive strength. These properties have been studied extensively for traditional concrete that uses ordinary Portland cement (OPC) as binder. The production of OPC has been associated with significant emission of $\mathrm{CO}_{2}$, a global problem that received significant attention in the past decades. Therefore, there is a renewed interest in studying alkali-activated natural or industrial byproducts as alternative binders to OPC. Studies have shown that long-term exposure of concrete to aggressive environment, such as freezing and thawing, or alkali-aggregate reaction may cause significant loss of strength and impair load-carrying capacity of structural elements [1]. The penetrability of concrete pore system is a measure of its performance in aggressive environment, and has therefore been linked to its durability and long-term resilience. In unsaturated concrete, the rate of water ingress is controlled to great extent by 
absorption due to capillary rise. Studies have shown that ingress of water carrying harmful chlorides into concrete may lead to corrosion of reinforcing steel bars and jeopardize the integrity of the structural system [2]. The conveyance of chloride-bearing water to reinforcing steel through concrete is related fundamentally to the connectivity of the pore system, in addition to pore structure and microcracks. Fly ash and ground-granulated blast furnace slag (GGBS), individually or combined have demonstrated ability to enhance mechanical properties and durability, when used as concrete binders to partially replace OPC $[3,4]$.

A study by Collins and Sanjayan [5] showed that sorptivity of $63 \mathrm{~mm} \times 98 \mathrm{~mm}$ concrete samples produced using alkali-activated GGBS binders, increases mildly with time when samples are left unsealed under lab conditions at $23{ }^{\circ} \mathrm{C}$ and $50 \%$ relative humidity (RH). On the other hand, sorptivity decreased continuously for all samples cured in water or sealed but left in lab conditions, for all ages from 1 day to 96 days. Zhang and Zong [6] found that water absorption of $100 \mathrm{~mm} \times 175 \mathrm{~mm}$ OPC-based cylindrical concrete samples was higher when cured in the lab by direct exposure to air at $20 \pm 3{ }^{\circ} \mathrm{C}$ and $65 \pm 5 \% \mathrm{RH}$, compared to samples cured under water. On the other hand, water absorption was much less when the same concrete samples were air-cured at the same temperature $\left(20 \pm 3^{\circ} \mathrm{C}\right)$, but at higher relative humidity of $90 \pm 5 \%$. However, air-cured samples developed higher compressive strength than moist-cured samples, especially at higher levels of RH which is consistent with the literature [7].

Water absorption of mortars in which fly ash precursor was activated using a combination of $\mathrm{NaOH}$ and $\mathrm{Na}_{2} \mathrm{SiO}_{3}$ was found to be affected by curing temperature as well as the activator ratio $\mathrm{Na}_{2} \mathrm{SiO}_{3} / \mathrm{NaOH}$. Studies in which fly ash mortar samples were cured for $24 \mathrm{~h}$ initially at $100{ }^{\circ} \mathrm{C}$, absorbed less water than those cured at $70{ }^{\circ} \mathrm{C}$ for all ratios of $\mathrm{Na}_{2} \mathrm{SiO}_{3} / \mathrm{NaOH}$ including 1.0, 1.5, 2.0, 2.5, and 3.0. However, samples cured at $100{ }^{\circ} \mathrm{C}$ experienced increase in rate of water absorption with increase in activator ratio. At the lower curing temperature of $70{ }^{\circ} \mathrm{C}$, rate of water absorption decreased with increase in activator ratio [8].

Setting time and flowability are greatly enhanced with a balanced amount of fly ash in the binder mix, while GGBS enhances early strength development and carbonation resistance. Nedeljković et al. [9] indicated that increasing the content of GGBS in GGBS/fly ash binder mixes enhances carbonation resistance of alkali-activated mortar samples, regardless of curing conditions.

Calcium stearate (CaSt) in optimum dosages decreases sorptivity of alkali-activated slag compared to benchmark OPC mortar samples [10]. CaSt is hypothesized to enhance the pore system by decreasing pore connectivity/microcracks, and increasing entrained pores. The admixture also introduces a hydrophobic film on the pores that decreases water sorptivity. However, CaSt tends to decrease compressive strength of concrete.

Key combinations of GGBS and fly ash that offered promising results in the literature are $50 \%$ GGBS $+50 \%$ fly ash and $75 \%$ GGBS $+25 \%$ fly ash, which are evaluated in this study, in addition to $100 \%$ GGBS mixes to serve as benchmark. Studies on alkali-activated GGBS as sole binder demonstrated significant benefits in terms of early strength development and durability of concrete, along with some shortcomings. Combining fly ash with GGBS as alkali-activated binders could alleviate the high shrinkage experienced by concrete/mortars when GGBS is used as sole binder [11].

When exposed to acid, early scaling and softening of OPC-based concrete has been observed due to decomposition of calcium hydroxide and formation of large amount of gypsum. As a result, long-term exposure of concrete to aggressive acid-rich environment, such as sewerage system, leads to severe degradation of strength $[12,13]$. The higher the content of OPC binder, the higher the mass loss due to exposure to sulfuric acid [14]. Theoretical studies by Ren et al. [15] predicted that, when subjected to sulfuric acid for 50 -years, $52 \%$ to $60 \%$ higher loss in compressive strength may occur in alkali-activated slag/fly ash concrete compared to OPC-based concrete.

Zhang et al. [16] reported that exposure of alkali-activated mortars to sulfuric acid for 28-days has negligible effect on mineralogical properties when fly ash is the sole binder and 
formation of gypsum was limited to the outer surface of samples, without propagating to inner core of the samples. After immersion in sulfuric acid for 28-days, the layers of mortar samples prepared using blends of GGBS/fly ash affected by sulfate attack, experienced reduction in $\mathrm{Al} / \mathrm{Si}$ ratio compared to layers or portions of the samples that were not affected by sulfate attack. In blends of GGBS and fly ash, the higher the percentage of GGBS the lower the effect of sulfuric acid, possibly due to the denser matrix and refined core structure formed by GGBS hydration products impeding progression of sulfuric acid.

Unlike mortars developed using alkali-activated GGBS as sole binder, exposure of fly ash-based mortar samples to $3 \%$ sulfuric acid for 90 days lead to severely compromised porosity. The increase in porosity system was attributed to the corrosive action of the acid and leaching of gypsum from the matrix [17]. Similarly, Bakharev [18] observed significant deterioration in strength along with loss of mass in geopolymer mortar samples prepared using class F fly ash and activated using sodium silicate and a mixture of sodium hydroxide and potassium hydroxide. Tests by Gu [19] showed that exposure of fly ash-based alkaliactivated mortars to even $1 \%$ sulphuric acid for 492 days results in significant loss of mass and strength. XRD studies by Lee and Lee [20] on alkali-activated GGBS/fly ash showed that exposure to $10 \%$ sulfuric acid causes formation of gypsum due to decalcification of C-A-S-H. Contrary to studies reported earlier in this section, the formation of gypsum along with weight was more severe when GGBS content is increased from 0 to $50 \%$ at the expense of fly ash content in the total alkali-activated binder [21].

Fly ash-based geopolymer mortars subjected to $\mathrm{MgSO}_{4}$ solution for 10 years experienced deeper penetration of sulfates compared to OPC-based mortar samples. However, OPC-based samples experienced more swelling and cracking compared to fly ash samples, due to formation of gypsum and ettrignite when sulfate ions reacted with $\mathrm{Ca}(\mathrm{OH})_{2}$ and calcium aluminate hydrate [19].

It was reported that certain organic acids prevalent in wastewater and other environments, such as acetic acid has more damaging effect on highly alkaline cementitious materials, compared to strong acids such as sulfuric acids [22]. Other studies, however, described damage to cement-based materials due to acetic acid as intermediate while citric acid causes severe degradation to cement matrix [23]. In general, blended GGBS/fly ash concrete/mortar had better resistance to organic acids commonly found in agricultural and food effluents, such as acetic and lactic acids, compared to OPC-based concrete/mortars [22]. The enhanced resistance of alkali-activated concrete/mortar to acidinduced deterioration was attributed to reduced amount of vulnerable phases such as calcium hydroxide and ettrignite, compared to OPC-based concrete/mortar which contains those vulnerable phases. The vulnerability of alkali-activated concrete/mortar when fly ash is used as sole binder to sulfuric acid motivates the need to evaluate binders containing both fly ash and GGBS to benefit from the known strengths that each of the two material bring to the finished product.

Concrete setting time is a critical property that affects workability and time needed to complete casting in professional practice, as well as time necessary to remove formwork in the case of cast-in-place (CIP) concrete structures. Study by Dehghani et al. [24] showed that in blended GGBS/fly ash mixes, the higher the percentage of GGBS the lower the initial and final setting times, and increasing the ratio of $\mathrm{SiO}_{2} / \mathrm{Al}_{2} \mathrm{O}_{3}$ decreases the setting time. In blends in which GGBS was decreased from $22 \%$ (78\% fly ash) to $4 \%$ ( $96 \%$ fly ash), the initial setting time increased from approximately $35 \mathrm{~min}$ to $60 \mathrm{~min}$, while the final setting time increased from approximately $55 \mathrm{~min}$ to nearly $100 \mathrm{~min}$. This is attributed to abundance of calcium (in the form of $\mathrm{CaO}$ ) in the GGBS precursor. Increasing fly ash content in the binder blend increases setting time due to the slow dissolution of fly ash and subsequent slow formation of polymerization products. Decrease in setting time in GGBS/fly ash blends where 70\% of the binder is GGBS or the entire binder is GGBS is also documented by Jang et al. [25].

Wardhono et al. [26] studied compressive strength development of $50 \mathrm{~mm}$ cubic mortar samples cured by submerging under water at ambient temperature and tested after 3, 7, 14, 
and 28 days. Binders consisting of GGBS, or combination of fly ash class F and GGBS were activated using a mixture of $15 \mathrm{M} \mathrm{NaOH}$ solution and sodium silicate solution. The activator solution was proportioned to achieve $15 \% \mathrm{Na}_{2} \mathrm{O}$ content and a modulus $\left(\mathrm{SiO}_{2} / \mathrm{Na}_{2} \mathrm{O}\right)$ of 1.25. Mixes were created with various binder ratios of GGBS/fly ash. With the exception of the mix with $100 \%$ GGBS, all mixes increased in compressive strength starting from 3 days of curing to 28 days. After 28-days of moist curing at ambient temperature, the mortar samples with 50\% GGBS and 50\% fly ash exhibited the highest compressive strength. The $100 \%$ GGBS mix developed the highest compressive strength at the age of 3 days, but by the age of 7-days, the mix with 50\%GGBS + 50\% fly ash developed higher compressive strength

Many studies identified the main reaction product of alkali-activated GGBS-fly ash concrete to be chain-structured C-A-S-H type gel [27]. In addition to C-A-S-H, the presence of fly ash promotes formation of sodium aluminosilicate (N-A-S-H) which is more porous and less compact than C-A-S-H [28]. Uppalapati et al. [29] reported that in the early hours after mixing GGBS-fly ash binder combination, only C-A-S-H is present due to the fast hydration of GGBS with little or no N-A-S-H. This is because dissolution of fly ash takes longer time than hydration of GGBS. Nonetheless, Lee et al. [30] reported identifying $\mathrm{C}-\mathrm{N}-\mathrm{A}-\mathrm{S}-\mathrm{H}$ as reaction product in early-hours after mixing GGBS-fly ash mortar samples. Studies consistently reported that increasing GGBS content in GGBS-fly ash binders results in denser matrix of the reaction products.

In unsaturated concrete, the rate of water ingress is controlled to great extent by absorption due to capillary rise. The industrial by-products GGBS and fly ash are sustainable alternatives to OPC, that offer high potential of producing durable concrete for infrastructure projects. Curing method, temperature, and relative humidity affect strength development in concrete that uses OPC as binder. Concrete in which up to $90 \%$ of OPC was replaced by selected combinations of GGBS, fly ash, silica fume developed higher 28-day compressive strength when cured in air at $45^{\circ} \mathrm{C}$ temperature and $70 \% \mathrm{RH}$, than similar OPC-based concrete cured under water in ambient laboratory conditions [31].

The objective of this study is to assess the effect of $\mathrm{NaOH}$ activator concentration (molarity), ratio of sodium silicate/sodium hydroxide (SS/SH), relative amount of GGBS and fly ash in binder mix, on the sorptivity setting time, and resistance to sulfuric acid attack of alkali-activated concrete.

\section{Methodology}

The experimental program was designed and implemented to evaluate initial/final setting times, sorptivity, and resistance to sulphuric acid of mortar samples considering the effect of alkalinity of the activator solution and the relative contents of GGBS/fly ash in the total binder content.

\subsection{Material Properties}

Alkali-activated binder used in this study is GGBS or combination of GGBS and fly ash and their properties are shown in Table 1. The binders were supplied by RMB Ready Mix, Abu Dhabi, United Arab Emirates. The percentages of calcium oxide ( $\mathrm{CaO})$, Silicon dioxide $\left(\mathrm{SiO}_{2}\right)+$ aluminum oxide $\left(\mathrm{Al}_{2} \mathrm{O}_{3}\right)+$ iron oxide $\left(\mathrm{Fe}_{2} \mathrm{O}_{3}\right)$, and Sulfur trioxide $\left(\mathrm{SO}_{3}\right)$ are all consistent with ASTM C618 [32] class F fly ash. Sodium hydroxide flakes and sodium silicates solution used to activate the binder were supplied Dubichem, Dubai, United Arab Emirates.

Table 1. Properties of ground granulated blast furnace slag and fly ash.

\begin{tabular}{cccccccccccccc}
\hline & $\mathrm{CaO}$ & $\mathrm{SiO}_{2}$ & $\mathrm{Al}_{2} \mathrm{O}_{3}$ & $\mathrm{SO}_{3}$ & $\mathrm{Fe}_{2} \mathrm{O}_{3}$ & $\mathrm{TiO}_{2}$ & $\mathrm{~K}_{2} \mathrm{O}$ & $\mathrm{MnO}$ & $\mathrm{SrO}$ & $\mathrm{ZrO}_{2}$ & $\mathrm{CuO}$ & $\mathrm{Cr}_{2} \mathrm{O}_{3}$ & $\mathrm{Y}_{2} \mathrm{O}_{3}$ \\
\hline $\begin{array}{c}\mathrm{GGBS} \\
(\%)\end{array}$ & 59.44 & 25.68 & 8.12 & 2.75 & 1.499 & 1.048 & 0.609 & 0.562 & 0.125 & 0.065 & 0.031 & 0.026 & 0.016 \\
\hline $\begin{array}{c}\mathrm{Fly} \\
\begin{array}{c}\text { Ash } \\
(\%)\end{array}\end{array}$ & 4.294 & 58.158 & 24.351 & 0.068 & 8.517 & 2.565 & 1.534 & 0.094 & 0.062 & 0.085 & 0.037 & 0.047 & 0.015 \\
\hline
\end{tabular}




\subsection{Experimental Procedure-Sorptivity}

The sorptivity of alkali-activated GGBS/fly ash mortar samples was evaluated using the methodology proposed by Hall [33] and adapted by ASTM C1585 [34]. The original test was developed to determine water absorption of hydraulic OPC. However, studies have shown that connected porosity, which controls transport properties of OPC-based and alkali-activated mortars are very similar [35,36]. The test measures the increase in the mass of a specimen resulting from absorption of water as a function of time through one surface of the specimen. The exposed surface of the specimen is immersed in water, and water ingress of unsaturated mortar specimens is dominated by capillary suction during initial contact with water. Measurement of sample weight and calculation of the rate of absorption offer a good indication of the continuity of pores within geopolymer mortar samples.

The activator solution was prepared by combining sodium hydroxide $(\mathrm{NaOH})$ and sodium silicate solutions. $\mathrm{NaOH}$ solution is prepared by adding calculated amounts of sodium hydroxide flakes to clean water to develop various mixes having molarities of $10 \mathrm{M}, 12 \mathrm{M}, 14 \mathrm{M}$, and $16 \mathrm{M}$. After adding $\mathrm{NaOH}$ flakes to water, the solution is covered for two hours to cool down as the reaction is exothermic. Sodium silicate solution was then added to the sodium hydroxide solution in appropriate quantities to create various alkaline activator solutions with modulus $\mathrm{n}=\mathrm{Na}_{2} \mathrm{SiO}_{3} / \mathrm{NaOH}$ of 1.5, 2.0, or 2.5. These alkaline activator mixtures $(1.5,2.0$, and 2.5$)$ were prepared for four sodium hydroxide mixes with molarities of $10 \mathrm{M}, 12 \mathrm{M}, 14 \mathrm{M}$, and $16 \mathrm{M}$ producing a total of 12 alkaline activator mixes for each of the three binder types. The three binder types are 100\% GGBS (G100), 75\% GGBS + $25 \%$ fly ash (G75F25), and 50\% GGBS + 50\% fly ash (G50F50). For sorptivity tests, $100 \mathrm{~mm}$ (diameter) $\times 50 \mathrm{~mm}$ (length) mortar samples were prepared for each of the 36 mixes.

Prior to preparing mortar samples, a polycarboxylic ether superplasticizer was added to the activator solution with adjusted dosage to enhance workability while limiting bleeding. The superplasticizer used is produced and marketed by BASF Corporation, Ludwigshafen, Germany, under the commercial name MasterGlenium SKY 504. The quantity of superplasticizer is $2.5 \%$ of the total binder content. The sand-to-binder-ratio is maintained at 2.75, while the activator solution-to-binder ratio was maintained at 0.55 for each of the 36 mixes. Table 2 shows the three binder groups based on GGBS and fly ash contents, and the corresponding 12 mixes for each of the three binder types, G100, G75F25, and G50F50.

Table 2. Mortar mixes tested in the program, based on binder type, molarity of $\mathrm{NaOH}$, and ratio of Sodium Silicate/Sodium Hydroxide.

\begin{tabular}{|c|c|c|c|c|c|c|c|c|c|c|c|c|}
\hline & \multicolumn{4}{|c|}{ G100 Mixes } & \multicolumn{4}{|c|}{ G75F25 Mixes } & \multicolumn{4}{|c|}{ G50F50 Mixes } \\
\hline & $\begin{array}{c}\text { GGBS } \\
(\%)\end{array}$ & $\begin{array}{l}\text { Fly } \\
\text { Ash } \\
(\%)\end{array}$ & $\begin{array}{c}\mathrm{NaOH} \\
\text { Molarity } \\
\text { (M) }\end{array}$ & SS/SH & $\begin{array}{c}\text { GGBs } \\
(\%)\end{array}$ & $\begin{array}{l}\text { Fly } \\
\text { Ash } \\
(\%)\end{array}$ & $\begin{array}{c}\mathrm{NaOH} \\
\text { Molarity } \\
\text { (M) }\end{array}$ & SS/SH & $\begin{array}{c}\text { GGBs } \\
(\%)\end{array}$ & $\begin{array}{l}\text { Fly } \\
\text { Ash } \\
(\%)\end{array}$ & $\begin{array}{c}\mathrm{NaOH} \\
\text { Molarity } \\
\text { (M) }\end{array}$ & SS/SH \\
\hline 1 & 100 & 0 & 10 & 1.5 & 75 & 25 & 10 & 1.5 & 50 & 50 & 10 & 1.5 \\
\hline 2 & 100 & 0 & 10 & 2 & 75 & 25 & 10 & 2 & 50 & 50 & 10 & 2 \\
\hline 3 & 100 & 0 & 10 & 2.5 & 75 & 25 & 10 & 2.5 & 50 & 50 & 10 & 2.5 \\
\hline 4 & 100 & 0 & 12 & 1.5 & 75 & 25 & 12 & 1.5 & 50 & 50 & 12 & 1.5 \\
\hline 5 & 100 & 0 & 12 & 2 & 75 & 25 & 12 & 2 & 50 & 50 & 12 & 2 \\
\hline 6 & 100 & 0 & 12 & 2.5 & 75 & 25 & 12 & 2.5 & 50 & 50 & 12 & 2.5 \\
\hline 7 & 100 & 0 & 14 & 1.5 & 75 & 25 & 14 & 1.5 & 50 & 50 & 14 & 1.5 \\
\hline 8 & 100 & 0 & 14 & 2 & 75 & 25 & 14 & 2 & 50 & 50 & 14 & 2 \\
\hline 9 & 100 & 0 & 14 & 2.5 & 75 & 25 & 14 & 2.5 & 50 & 50 & 14 & 2.5 \\
\hline 10 & 100 & 0 & 16 & 1.5 & 75 & 25 & 16 & 1.5 & 50 & 50 & 16 & 1.5 \\
\hline 11 & 100 & 0 & 16 & 2 & 75 & 25 & 16 & 2 & 50 & 50 & 16 & 2 \\
\hline 12 & 100 & 0 & 16 & 2.5 & 75 & 25 & 16 & 2.5 & 50 & 50 & 16 & 2.5 \\
\hline
\end{tabular}

After demolding, the $100 \mathrm{~mm} \times 50 \mathrm{~mm}$ samples were left in the laboratory until the sorptivity test date, which was done after 7 days, 28 days, and 90 days. Each sample was 
oven dried, then sealed with duct tape on each side, except the bottom, which will be in contact with water. Weight of sample was determined using $0.01 \mathrm{~g}$ scale while dry, prior to placement on water. The samples were then placed so that 1 to $2 \mathrm{~mm}$ of the sample is immersed in water, as shown in Figure 1. The samples were then removed from the water box and weighed after 1, 5, 10, 20, and 30 min of base immersion. Sample weights were then measured each one hour since the beginning of sample base immersion.

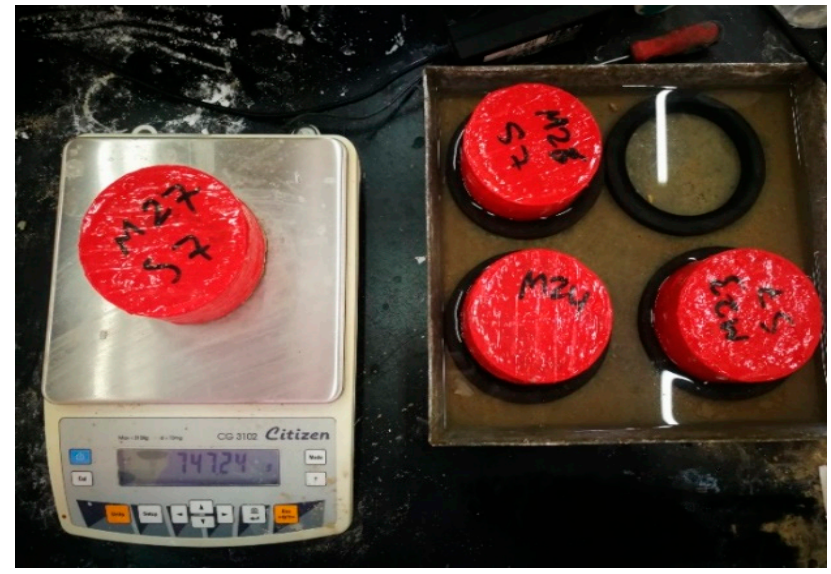

(a)

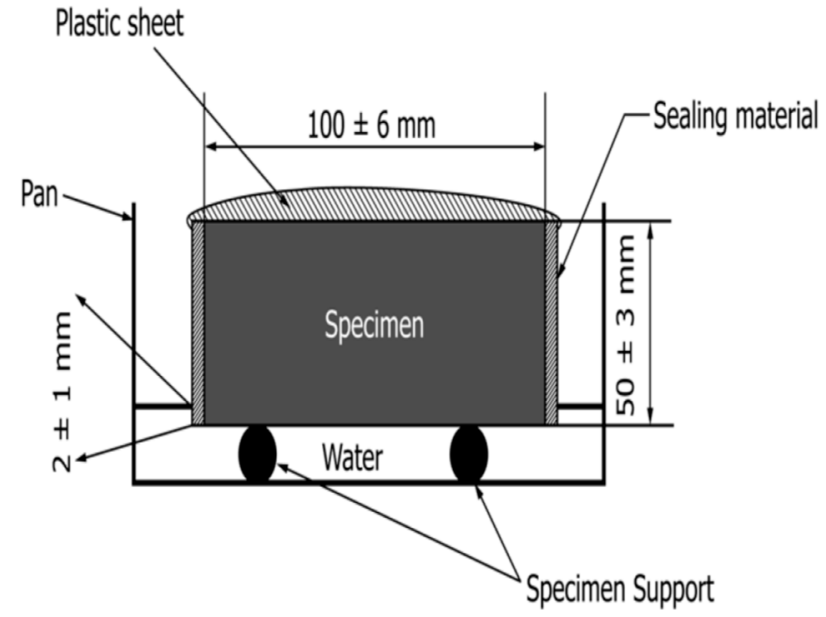

(b)

Figure 1. (a) Mortar samples immersed in water for the specified period of time, then weighed, (b) schematic for immersion level and sealing system/sides.

The weights of samples at each of the specified times are measured as discussed earlier, and the absorption of sample is calculated using Equation (1).

$$
I=\frac{m_{t}}{a \times d}
$$

where:

$I=$ absorption

$m_{t}=$ the change in specimen mass in grams, at the time $t$

$a=$ the exposed area of the specimen, in $\mathrm{mm}^{2}$, and

$d=$ the density of water, taken as $0.001 \mathrm{~g} / \mathrm{mm}^{3}$

A common model for the relationship between the absorption and the square root of time for the first six hours of absorption measurement is given by Equation (2) [ASTM C1585]. The linearity of the relationship between the water absorption " $I$ " and the square root of time was validated in several studies [34].

$$
I=S_{i} \sqrt{t}+b
$$

where:

$S_{i}=$ initial rate of absorption, $\mathrm{mm} / \sqrt{\mathrm{s}}$.

\subsection{Experimental Procedure-Resistance to Sulfuric Acid Attack}

Response of alkali-activated mortar samples to sulfuric acid exposure was assessed using ASTM C267 [37] test procedure. $20 \mathrm{~mm}$ cubic samples were prepared and left in molds for $24 \mathrm{~h}$, then demolded and weighed using $0.01 \mathrm{~kg}$ scale. Samples were then submerged in $10 \%$ sulfuric acid $\left(\mathrm{H}_{2} \mathrm{SO}_{4}\right)$ until the test day. After 7-days, 28-days, and 90-days of curing, samples were surface-dried, weighed, and the change in weight was determined. Sufficient specimens were cast so the results were the average of three samples for each 
target parameter including activator ratio, curing age, molarity, and binder combination. The percentage change in sample weight was calculated using Equation (3).

$$
\text { weight change }(\%)=[(W-C) / C] \times 100
$$

where:

$C=$ conditioned weight of the specimen (grams)

$W=$ weight of specimen after immersion (grams)

\subsection{Initial and Final Setting Times}

One of the goals of this study is to evaluate the effects of two factors on the initial and final setting times: (1) the relative amounts of GGBS and fly ash in the total binder content, and (2) the molarity of sodium hydroxide $(\mathrm{NaOH})$ activator. The setting time of the mixes described earlier was determined using ASTM C191 and calculated Vicat time (minutes) is given by:

$$
\left(\left(\frac{H-E}{C-D}\right) \times(C-25)\right)+E
$$

where:

$E=$ time in minutes of the last penetration greater than $25 \mathrm{~mm}$.

$H=$ time in minutes of the first penetration less than $25 \mathrm{~mm}$.

$C=$ penetration reading at time $E$, and

$D=$ penetration reading at time $H$.

\section{Results and Discussion}

\subsection{Sorptivity and Mass Loss}

Figure 2 shows the calculated initial rate of absorption $s_{i}(\mathrm{~mm} / \sqrt{\mathrm{s}})$ for G100 mortar samples activated with sodium hydroxide and sodium silicates solution combined so that the alkaline activator ratio $\mathrm{Na}_{2} \mathrm{SiO}_{3} / \mathrm{NaOH}$ is $1.5,2.0$, or 2.5. Mortar sample were created with these three activator ratios for each of four $\mathrm{NaOH}$ molarities: $10 \mathrm{M}, 12 \mathrm{M}, 14 \mathrm{M}$, and $16 \mathrm{M}$. In general, the higher the ratio of $\mathrm{Na}_{2} \mathrm{SiO}_{3} / \mathrm{NaOH}$ the lower the sorptivity of mortar samples, especially for higher molarities of the $\mathrm{NaOH}$ activator $(14 \mathrm{M}$ and $16 \mathrm{M})$. It is also clear that for each activator ratio $(1.5,2.0$, or 2.5$)$, sorptivity decreases with curing age and the phenomenon is true for all of the four $\mathrm{NaOH}$ moralities. This is because more hydration and polymerization products develop over time which results is filling more voids. It was reported that in slag-fly ash blends, where slag content is greater than or equal $50 \%$, spacing-filling calcium (alumina) silicate hydrate gel provides porosity reductions not observed in sodium aluminosilicate geopolymer gels [38].

Figure 3 shows the influence of $\mathrm{Na}_{2} \mathrm{SiO}_{3} / \mathrm{NaOH}$ ratio on sorptivity of alkali-activated G50F50 mortar samples. Figure 3A-D represent sorptivity of samples prepared with $\mathrm{NaOH}$ molarity of $10 \mathrm{M}, 12 \mathrm{M}, 14 \mathrm{M}$, and $16 \mathrm{M}$ respectively. Similar to the pattern with G100, sorptivity decreases with curing age, for each $\mathrm{NaOH}$ molarity and for each $\mathrm{Na}_{2} \mathrm{SiO}_{3} / \mathrm{NaOH}$ ratio considered in this study. Mortar samples prepared with $\mathrm{Na}_{2} \mathrm{SiO}_{3} / \mathrm{NaOH}$ ratio of 2.0 experienced the lowest sorptivity when tested after each of the three curing ages $(7,28$, and 90 days) for samples prepared with $\mathrm{NaOH}$ molarities of $10 \mathrm{M}, 14 \mathrm{M}$, and $16 \mathrm{M}$. This ratio appears to represent the optimum sodium to produce polymerization products such as calcium sodium aluminosilicate hydrate (C-N-A-S-H) from the fly ash precursor, which represents $50 \%$ of the total binder. At the age of 28-days and alkaline activator ratio of 2.0, sorptivity ranged from $3.66 \mu \mathrm{mm} / \sqrt{\mathrm{s}}$ when $\mathrm{NaOH}$ molarity was $10 \mathrm{M}$, to $1.46 \mu \mathrm{mm} / \sqrt{\mathrm{s}}$ when $\mathrm{NaOH}$ molarity increased to $16 \mathrm{M}$. Hydration of the other 50\% GGBS continues and produces products such as calcium aluminosilicate hydrate (C-A-S-H) and decreases the voids. The decrease in sorptivity with increase in alkaline activator molarity of G50F50 will be shown in subsequent sections of this article to be consistent with the increase in compressive strength with increase in solution alkalinity. 
A: Sorptivity of G100 Mortars - 10M NaOH

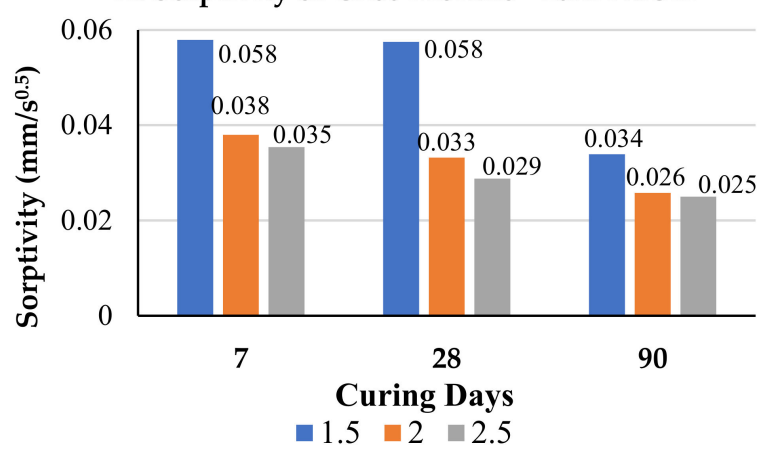

C: Sorptivity of G100 Mortar- M14 NaOH

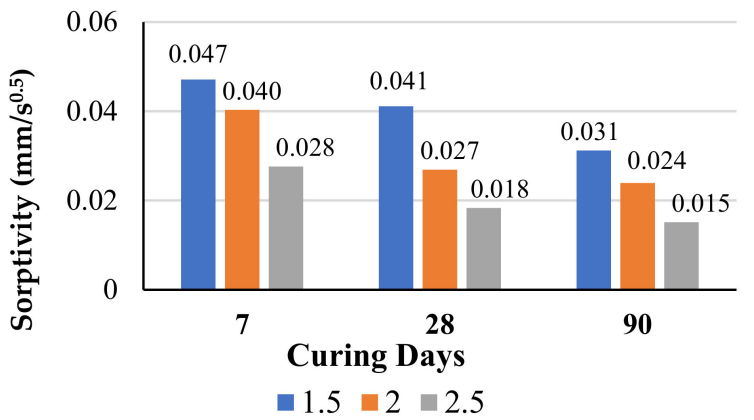

B: Sorptivity of G100 Mortar - 12M NaOH

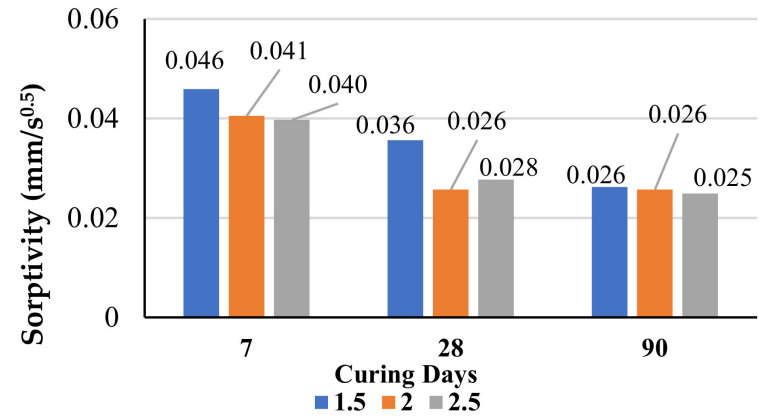

D: Sorptivity of G100 Mortar- M16 NaOH

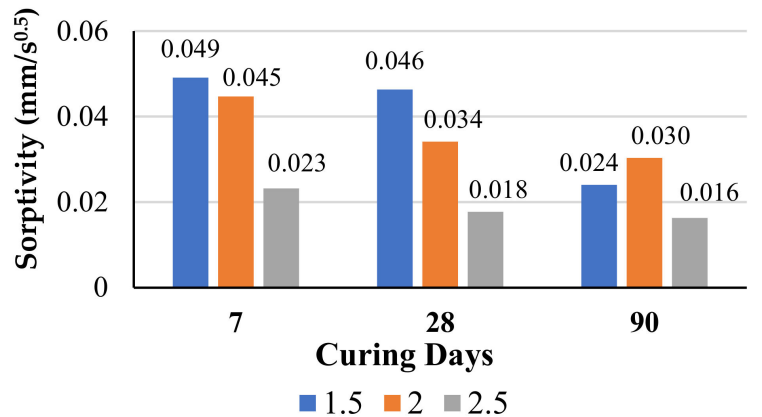

Figure 2. Effect of $\mathrm{Na}_{2} \mathrm{SiO}_{3} / \mathrm{NaOH}$ ratio sorptivity of $100 \%$ GGBS alkali activated mortar specimens when molarity of $\mathrm{NaOH}$ is: (A) $10 \mathrm{M}$, (B) $12 \mathrm{M}$, (C) $14 \mathrm{M}$, (D) $16 \mathrm{M}$.

A: Sorptivity of G50F50 - 10M NaOH

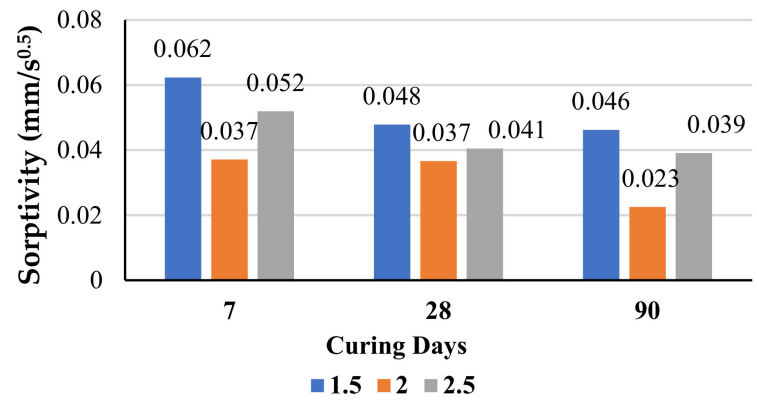

C: Sorptivity of G50F50 - 14M NaOH

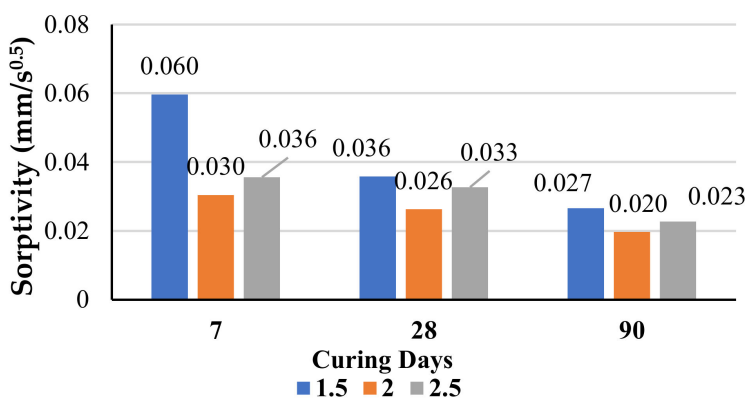

B: Sorptivity of G50F50 - 12M NaOH

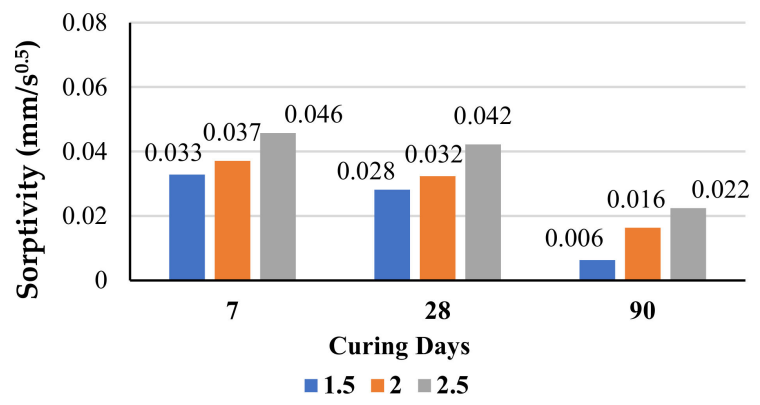

D: Sorptivity of G50F50 - 16M NaOH

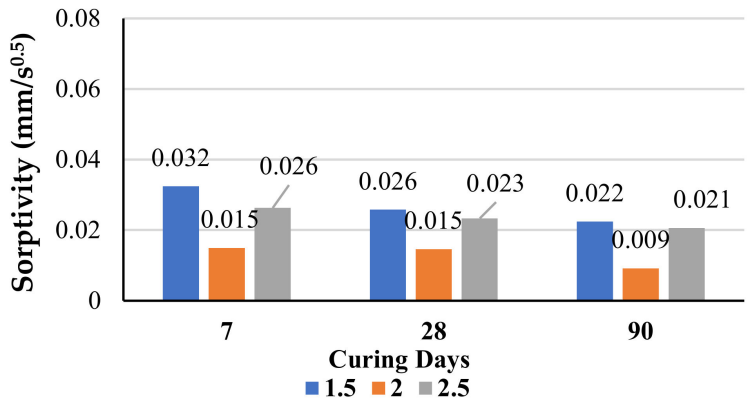

Figure 3. Effect of $\mathrm{Na}_{2} \mathrm{SiO}_{3} / \mathrm{NaOH}$ ratio Sorptivity of $50 \%$ GGBS $+50 \%$ fly ash alkali activated mortar specimens when molarity of $\mathrm{NaOH}$ is: (A) $10 \mathrm{M}$, (B) $12 \mathrm{M}$, (C) $14 \mathrm{M}$, (D) $16 \mathrm{M}$.

The variation of sorptivity rate with curing age for the three binder types/combinations including G100, G75F25, and G50F50 is shown in Figure 4 for NaOH molarities of 10 M, 
$12 \mathrm{M}, 14 \mathrm{M}$, and $16 \mathrm{M}$. The lowest sorptivity after 7 days, 28 days, or 90 days of curing is exhibited by G75F25 for $\mathrm{NaOH}$ molarities of $10 \mathrm{M}, 12 \mathrm{M}$, and $14 \mathrm{M}$. For $\mathrm{NaOH}$ molarity of $16 \mathrm{M}$, G50F50 mortars developed the lowest sorptivity after 7, 28, and 90 days of curing compared to the other two binder combinations. For all $\mathrm{NaOH}$ molarities and for each of the three binder combinations, sorptivity decreased with increase in sample curing age. This due to the formation of more hydration and polymerization products. Similarly, increasing fly ash content from $25 \%$ to $50 \%$ increased sorptivity after each curing age of 7, 28, and 90 days and for molarities of $\mathrm{NaOH}$ of $10 \mathrm{M}, 12 \mathrm{M}$, and $14 \mathrm{M}$. This is consistent with the findings of Mehta [39] for mortar samples tested at the age of 28 days, where increasing GGBS content up to $20 \%$ in fly ash-GGBS blends for a particular molarity decreased sorptivity. This is because of the slow dissolution of fly ash and formation of polymerization products at ambient temperature which delays of filling of voids when fly ash content is high. Curing temperature generally affects both hydration of OPC and polymerization of fly ash, therefore, influences rate of strength development [40,41].

A: $10 \mathrm{M} \mathrm{NaOH}$

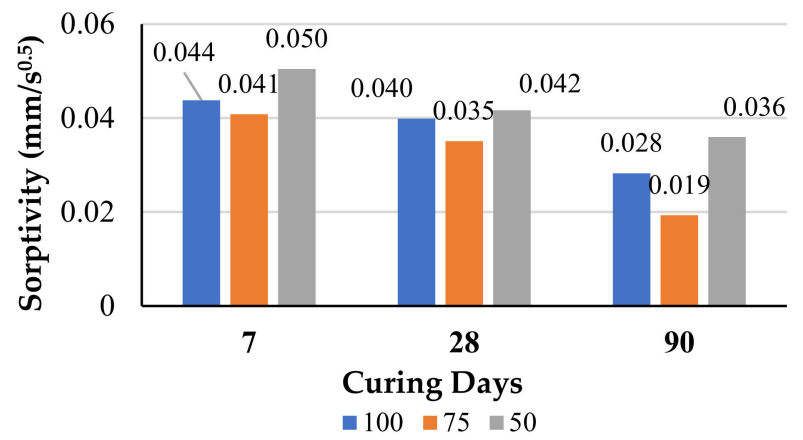

$\mathrm{C}: 14 \mathrm{M} \mathrm{NaOH}$

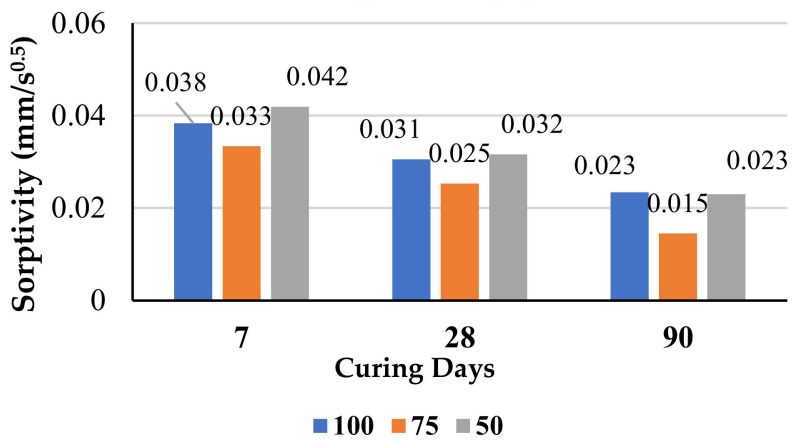

\section{B: $12 \mathrm{M} \mathrm{NaOH}$}

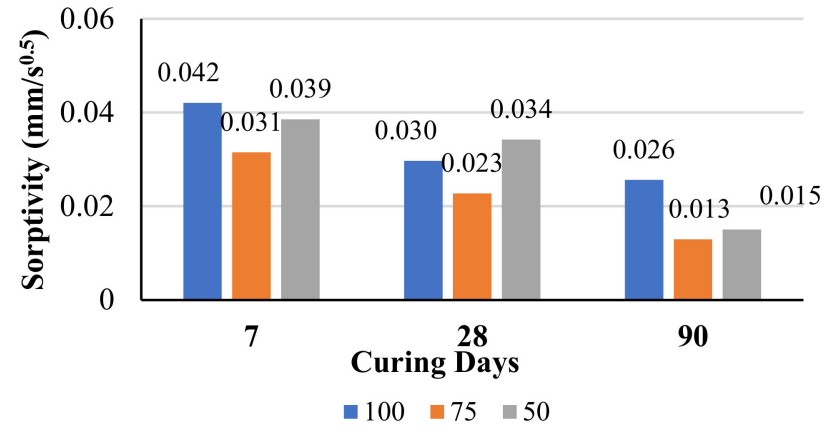

D: $16 \mathrm{M} \mathrm{NaOH}$

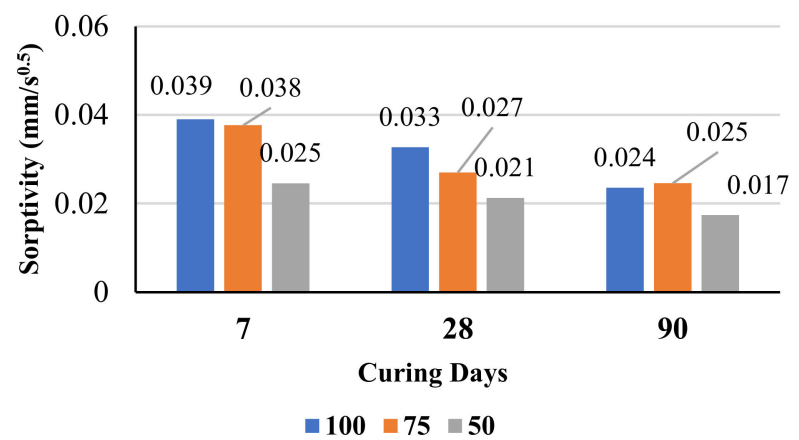

Figure 4. Change of sorptivity with curing age of $100 \% \mathrm{GGBS}, 75 \% \mathrm{GGB}+25 \% \mathrm{FA}$, and $50 \% G G B+50 \%$ FA, for molarity of $\mathrm{NaOH}$ of: (A) $10 \mathrm{M}$, (B) $12 \mathrm{M}$, (C) $14 \mathrm{M}$, and (D) $16 \mathrm{M}$.

\subsection{Effect of Exposure to Sulfuric Acid on Mass of Alkali-Aactivated GGBS-Fly Ash Mortar}

As discussed in the introduction of this paper, extended exposure of concrete to acid may lead to loss of mass and strength. Figure 5 shows the change in sample weight due to submersion of mortar samples in $10 \%$ sulfuric solution. In general, mortar samples weight increased with increase in activator ratio from 1.5 to 2.5 and the pattern was consistent for each of the three binder combinations G100, G75F25, and G50F50. Therefore, sulfate attack did not cause loss of mass over time, instead, curing the samples under water caused increase in weight due to formation of geopolymerization and hydration products. The formation of geopolyermization and hydration products outpaced any decalcification or dealumination that may have been caused by acid attack, largely due to the co-existence of fly ash and GGBS in quantity greater than $50 \%$. In contrast, it was reported in the 
literature that when fly ash is used as sole binder in alkali-activated mortars, loss of mass may occur as early as 14 days after immersion in acid solution [19]. As discussed in the previous sections, sorptivity decreased with time for all binder combinations and alkaline activator concentrations, which is consistent with increase in mass reported in this section. Similarly, in subsequent sections of this paper, it will be shown that compressive strength also increases with time.

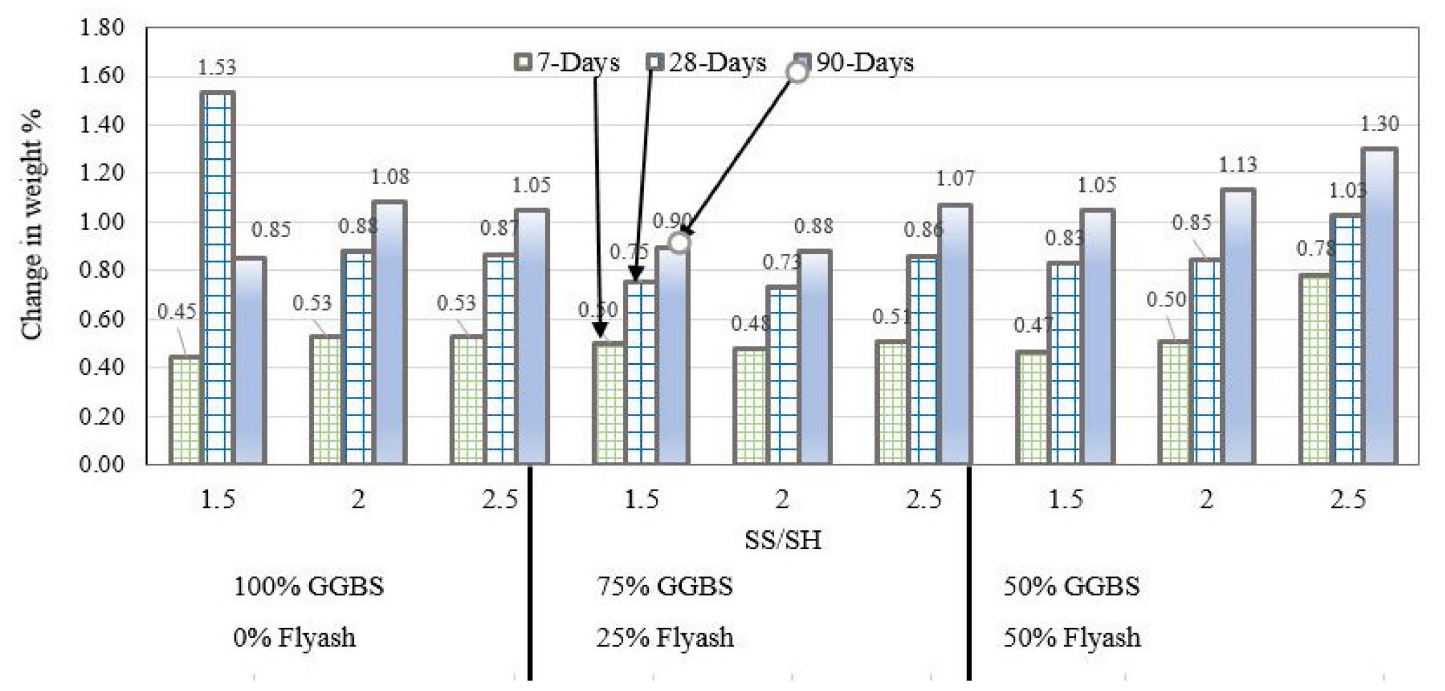

Figure 5. Weight change due to submission of mortars in 10\% sulfuric acid for G100, G75F25, and G50F50 binders.

\subsection{Effect of $\mathrm{NaOH}$ Molarity on Initial Setting (IS) and Final Setting (FS) Times}

Initial setting (IS) and final setting (FS) times are critical fresh properties for successful use of concrete with alkali-activated GGBS and fly ash binders. The effect of molarity of $\mathrm{NaOH}$ and relative contents of GGBS/fly ash in binder are discussed in this section.

Figure 6 shows the initial and final setting times for each of the three binder combinations and 4 values of $\mathrm{NaOH}$ molarity. G100 mortar samples exhibited decrease in both initial and final setting times with increase in molarity of the $\mathrm{NaOH}$ activator. The initial setting time was very short ranging from $20.33 \mathrm{~min}$ for $10 \mathrm{M} \mathrm{NaOH}$ to $11.5 \mathrm{~min}$ for 16 $\mathrm{M} \mathrm{NaOH}$. The final setting time was also short ranging from 43.67 min for $10 \mathrm{M} \mathrm{NaOH}$ to $26.17 \mathrm{~min}$ for $16 \mathrm{M} \mathrm{NaOH}$. Increasing the molarity of $\mathrm{NaOH}$ for G100 mortar samples increases the supply of calcium and formation of calcium silicates gel, which shortens both initial and final setting times. Calcium is abundant in GGBS precursor in the form of $\mathrm{CaO}$. The fast dissolution of $\mathrm{Al}$ and $\mathrm{Si}$, in addition to abundance of calcium, modifies the network and forms reaction products at faster rate [29].

G75F25 mortars exhibited an increase in initial and final setting times with increase in molarity of the activator $\mathrm{NaOH}$, except for $16 \mathrm{M}$ where setting time decreased compared $14 \mathrm{M}$. The presence of $25 \%$ fly ash in the binder increases both initial and final setting time compared to $100 \%$ GGBS binder for each value of the $\mathrm{NaOH}$ molarities. This is due to the inherently slow polymerization of fly ash. Initial setting time for G75F25 ranges from $19.67 \mathrm{~min}$ to $31 \mathrm{~min}$, depending on $\mathrm{NaOH}$ concentration.

The effect of higher amounts of GGBS in alkali-activated GGBS/fly ash is to decrease the setting time as shown in Figure 6A,B, which is consistent with the literature [27]. The fast setting time associated with the presence of GGBS may be addressed in various ways, such as the addition of up to $2 \%$ microsilica [29]. Borax may also be used to increase setting time [42].

When the amount of fly ash is increased to $50 \%$ of the total binder, the initial and final setting times increase significantly as a results of longer time needed to polymerize a larger amount of fly ash in the binder. Initial setting time of G50F50 mortar ranged from $30 \mathrm{~min}$ to $45 \mathrm{~min}$, while the final setting time ranged from $75.5 \mathrm{~min}$ to $108.3 \mathrm{~min}$. 
In general, the setting time of all mixes made with these three binders is relatively short compared to $100 \%$ fly ash geopolymer concrete and compared to OPC-based concrete. The short setting time of all three mixes, at room temperature is due to the presence of GGBS which hydrates and releases calcium into the system, and speeds up the formation of calcium silicates gel. In addition, it was shown that the higher the initial ratio of $\mathrm{SiO}_{2} / \mathrm{Al}_{2} \mathrm{O}_{3}$ in the mix, the lower the initial setting time, which is the case in binders with higher GGBS contents [26].

Figure $6 \mathrm{~B}$ shows that the final setting for G100 mortars, decreases with increase in the molarity of $\mathrm{NaOH}$. Once $25 \%$ fly ash is added (G75F25), final setting time increases compared to G100 mortars, but the trend remains that setting time increases with molarity of activator $\mathrm{NaOH}$. When the percentage of fly ash is further increased to $50 \%$ (G50F50), setting time increases further compared to G100 and G75F25, but the trend now reverses so that an increase in molarity decreases the setting. This latter trend is consistent with the findings of Lee and Lee [43] although, in that study, the molarity of $\mathrm{NaOH}$ was increased from $4 \mathrm{M}$ to $8 \mathrm{M}$ and the fly ash to GGBS ratio was $4: 1$.

A: Initial Setting Time

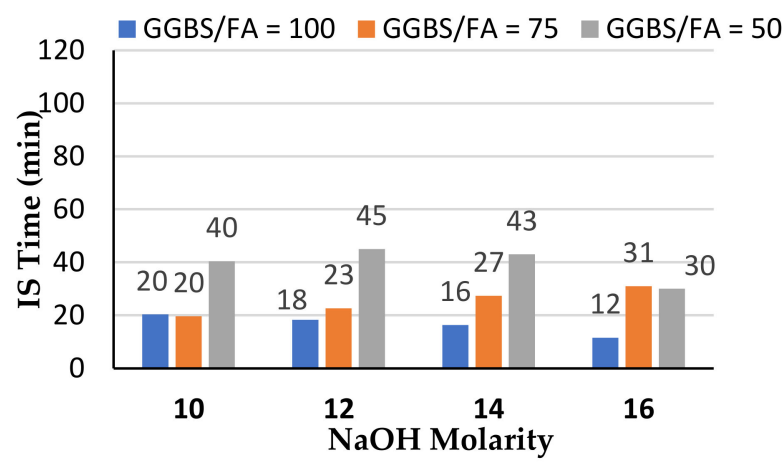

B: Final Setting Time

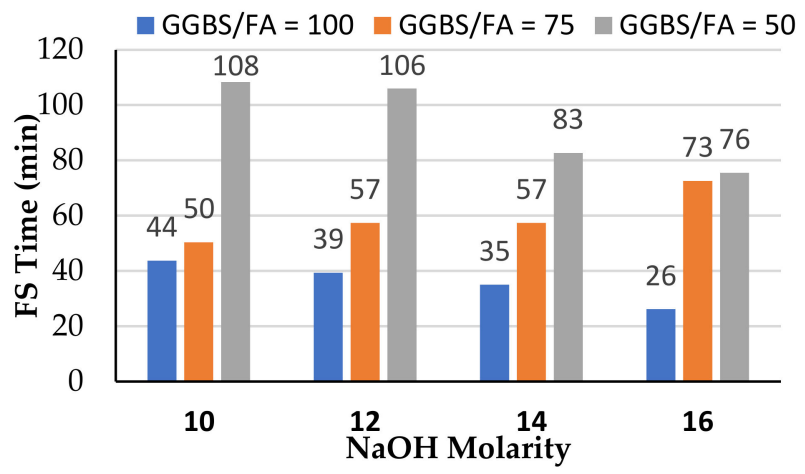

Figure 6. Variation of setting time with molarity of $\mathrm{NaOH}$ activator for $100 \%$ GGBS binder, $75 \%$ GGBS+25\%FA binder, and 50\%GGBS+50\%FA binder (A) initial setting time (IST), (B) final setting time.

\subsection{Effect of 10\% Sulfuric Acid Solution on Compressive Strength Development}

To observe the effect of sulfuric acid on compressive strength development, samples were tested in compression at the ages of 7-days, 28-days, and 90-days. As discussed earlier, mortar samples were removed from moulds $24 \mathrm{~h}$ after casting, and were then placed in $10 \%$ sulfuric acid until compression test day.

Table 3 shows the compressive strength of the cubic mortar samples prepared using $100 \%$ GGBS, 75\%GGBS + 25\% fly ash, and 50\% GGBS + 50\% fly ash. Each compressive strength value in the table is a function of binder type, alkaline activator ratio sodium silicate/sodium hydroxide (SS/SH), and molarity of $\mathrm{NaOH}$ alkaline activator.

After 7 days of curing under $10 \%$ sulfuric acid, the highest compressive strength of $56.96 \mathrm{MPa}$ was developed by the G75F25 mix when the molarity of $\mathrm{NaOH}$ was $10 \mathrm{M}$ and $\mathrm{SS} / \mathrm{SH}=1.5$, although G100 developed a statistically similar compressive strength of $56.66 \mathrm{MPa}$ at the same $\mathrm{NaOH}$ molarity and SS/SH ratio. This is due to the fast dissolution of GGBS in the early days after, compared to the slower polymerization of fly ash, especially at ambient temperature of $22 \pm 20 \mathrm{C}$ in which the samples in this study were cured. This is consistent with published literature on reaction products of $80 \% / 20 \%$ GGBS/fly ash blends where C-A-S-H was detected after one day of mixing and attributed to the abundance of $\mathrm{Ca} 2+$ ions that are readily available to react with $\mathrm{Si}$ and $\mathrm{Al}$ ions leading to precipitation of C-A-S-H gel, while no N-A-S-H was found at such early age [31].

After 28-days of curing, G75F25 continued to develop the highest compressive strength of $80.53 \mathrm{MPa}$ compared to G100 and G50F50 mixes. This indicates GGBS not only continued to hydrate at a fast rate, but also accelerated the polymerization of the $25 \%$ fly ash in G75F25 
mixes leading to increase in hydration and polyermization products. For this optimum combination of $75 \%$ GGBS and $25 \%$ fly ash to increase compressive strength to its highest value at the age of 28 -days, $\mathrm{NaOH}$ molarity needed to increase to $12 \mathrm{M}$. The high 28 -day compressive strength, even with relatively high liquid-to-binder ratio of 0.55 is attributed to the optimum compactness of the system consisting of dense less porous C-A-S-H due to the high content of GGBS, combined with smaller amount of the more porous hardened matrix of N-A-S-H. The larger permeable voids of N-A-S-H compared to the denser and smaller pore system of C-A-S-H is extensively documented in the literature [30,37].

After 90 days of curing, G75F25 continued to develop the highest compressive strength of $91.06 \mathrm{MPa}$, compared to the other two binders. The concentration of activator $\mathrm{NaOH}$ was the lowest of $10 \mathrm{M}$ or $12 \mathrm{M}$ when G75F25 reached the highest compressive strength after 90 days, due to the relatively small amount of fly ash. However, G50F50, which contains the highest fly ash content in this study, developed $86.73 \mathrm{MPa}$ after 90 days of curing when $\mathrm{NaOH}$ concentration was $16 \mathrm{M}$, which is very close in magnitude to the highest strength achieved by G75F25 during the same period of time. This was the case because the high alkalinity of the solution facilitated polymerization of larger amounts of the residual $50 \%$ fly ash during the 90 days of submersion under water. The dissolution of fly ash contributed higher amounts of silicates and aluminates, along with the higher supply of sodium ions through $\mathrm{NaOH}$ led to formation of N-A-S-H and caused the observed significant increase in compressive strength. The effect of high solution alkalinity on compressive strength, in relation to the content of fly ash is further evidenced after 90 days by comparing the strengths of G100, G75, and G50F50. The least compressive strength after 90 days with $16 \mathrm{M} \mathrm{NaOH}$ was developed by G100 mortar, while the highest was developed by either G75F25 or G50F50, each of them contains higher content of fly ash compared to G100. However, it is documented that the pore system produced in GGBS-fly ash blends when GGBS content is high, is denser and more compact, compared to the matrix produced with high fly ash content [27]. It may therefore be hypothesized that while the pore structure of the matrix formed by polymerization of fly ash is coarse and permeable, when fly ash content less than or equal to $50 \%$, it still contributes significantly to long-term compressive strength development when samples are water cured. This is possibly due to the effective filling of the porous pore system contributed by fly ash with the finer and denser pores developed by GGBS.

When cured in water under ambient temperature, lower $\mathrm{NaOH}$ concentration $(10 \mathrm{M}$ and $12 \mathrm{M}$ ) enhances the strength development when fly ash content is low (less than 50\% in this study), while higher $\mathrm{NaOH}$ concentration (16 M in this study) contributes to higher strength, in the long term when fly ash content is relatively high (50\% in this study).

Table 3. Compressive strength development of mortar samples cured in $10 \%$ sulfuric acid solution for G100, G75F25, G50F50 for various concentration of $\mathrm{NaOH}$ and three ratios of sodium silicate/sodium hydroxide.

\begin{tabular}{ccccccccccc}
\hline & \multicolumn{3}{c}{ 7 Days } & \multicolumn{3}{c}{ 28 Days } & \multicolumn{3}{c}{ 90 Days } \\
\hline $\begin{array}{c}\text { NaOH } \\
\text { Molarity }\end{array}$ & SS/SH & G100 & G75F25 & G50F50 & G100 & G75F25 & \multirow{2}{*}{ G50F50 } & G100 & G75F25 & G50F50 \\
\hline $10 \mathrm{M}$ & 1.5 & 56.66 & 56.96 & 43.66 & 66.86 & 61.83 & 55.43 & 74.56 & 81.66 & 74.6 \\
$10 \mathrm{M}$ & 2 & 39.53 & 40.96 & 26.5 & 61.2 & 75 & 53.23 & 45.63 & 91.06 & 70.86 \\
$10 \mathrm{M}$ & 2.5 & 45.1 & 50.46 & 26.83 & 36.53 & 69.93 & 45.3 & 39.43 & 88.23 & 66.13 \\
$12 \mathrm{M}$ & 1.5 & 22 & 35.5 & 29.23 & 47.26 & 65.13 & 44.93 & 37.03 & 73.9 & 66.66 \\
$12 \mathrm{M}$ & 2 & 31.9 & 34.63 & 29.3 & 40.7 & 56.83 & 52.96 & 48.93 & 84.03 & 67.63 \\
$12 \mathrm{M}$ & 2.5 & 56.3 & 39.93 & 28.4 & 62 & 80.53 & 53.4 & 62.73 & 87.06 & 69.36 \\
$14 \mathrm{M}$ & 1.5 & 35.76 & 39.16 & 26.76 & 53.3 & 45.96 & 40.76 & 54.16 & 60.96 & 62.7 \\
$14 \mathrm{M}$ & 2 & 43.5 & 44.73 & 33.03 & 56.63 & 60.53 & 51.9 & 73 & 80.23 & 73.83 \\
$14 \mathrm{M}$ & 2.5 & 49.6 & 39.3 & 36.73 & 58.93 & 69.13 & 56.23 & 73.5 & 79.9 & 79.83 \\
$16 \mathrm{M}$ & 1.5 & 22.63 & 19.13 & 27.63 & 36.93 & 38 & 38.06 & 37.96 & 51.26 & 63.53 \\
$16 \mathrm{M}$ & 2 & 42.43 & 47.76 & 44.06 & 50.93 & 65.56 & 69.2 & 51.8 & 78.06 & 86.73 \\
$16 \mathrm{M}$ & 2.5 & 32.33 & 39.7 & 37.53 & 63.13 & 61.26 & 52.26 & 70.03 & 83.03 & 74.06 \\
\hline
\end{tabular}

It is clear now that submersion of mortar samples that use GGBS-fly ash blends as binder in $10 \%$ sulfuric acid solution for up to 90 days doesn't cause reduction in mass 
nor compressive strength. Fly ash matrix is typically more susceptible to damage due to sulfuric acid, but in the present study it is limited to $50 \%$ of the total binder content. We now examine the effect of $\mathrm{NaOH}$ concentration, and binder composition on compressive strength development. Figure 7A-D, show the development of compressive strength with curing age for $\mathrm{NaOH}$ molarities of $10 \mathrm{M}, 12 \mathrm{M}, 14 \mathrm{M}$, and $16 \mathrm{M}$.

After 7 days of curing, mortar samples with the largest concentration of GGBS, such as G100 developed the highest compressive strength, due to the fast dissolution of GGBS compared to fly ash. As shown in Figure 7A-C, G100 developed higher or similar 7-day compressive strength as G75F25 mortars for all concentrations of the activator $\mathrm{NaOH}$, while the strength of G50F50 mortars was relatively low, dominated by the slow polymerization of fly ash. However, Figure 7D, corresponding to $\mathrm{NaOH}$ molarity of $16 \mathrm{M}$, shows that G75F25 and G50F50 developed similar 7-day compressive strength, that is slightly higher than the G100 mix. This due to the higher supply of sodium from the $16 \mathrm{M} \mathrm{NaOH}$ forming sodium-aluminate-silicate hydrates, although at slow rate.

As reaction and polymerization continue to 28-days, G75F25 mortar samples developed higher compressive strength than G100 and G50F50. As shown in Figure 7A, the average 28-day compressive of G75F25 mortars was nearly $69 \mathrm{MPa}$, the highest of the three binder combinations which certainly classifies as high strength concrete for most practical applications. Nonetheless, G50F50, affected by low dissolution of fly ash still developed 28-day of 51.33 MPa, also high strength for structural engineering applications. This is different from the data published by $\mathrm{Hu}$ [38] which showed that 28-day compressive strength to increases with increase in GGBS content, without an optimum GGBS content. The $10 \mathrm{M}$ molarity is the optimum $\mathrm{NaOH}$ concentration for 28-day compressive strength development for the G75F25 binder. Figure 7A-C shows that G100 mortars decreased in compressive strength at the age of 28 days, below G75F25, regardless of the alkaline activator concentration, but remain higher than or equal to G50F50 samples, indicating larger percentage of GGBS was consumed through formation of hydration products for $\mathrm{NaOH}$ concentrations of $10 \mathrm{M}, 12 \mathrm{M}$, and $14 \mathrm{M}$. At $\mathrm{NaOH}$ concentration of $16 \mathrm{M}$, the 28-day compressive strength of G50F50 reaches that of G75F25, but exceeds G100, similar to the 7 -day situation discussed in the previous section.

After 90 days of curing, G75F25 continued to dominate compressive strength performance of the three binders, reaching an impressive average strength of $87 \mathrm{MPa}$ as shown in Figure 7A. This confirms $\mathrm{NaOH}$ concentration of $10 \mathrm{M}$ is optimum for compressive strength development of GGBS-fly ash binders and alkaline activator concentrations covered in this study. After 90 days of curing, G50F50 mortars reached compressive strength of $74.7 \mathrm{MPa}$, surpassing the compressive strength of G75F25 as well as G100 for NaOH concentration of $16 \mathrm{M}$, as shown in Figure 7D. Recall that the strength of G75F25 was essentially equal to G50F50 samples at $16 \mathrm{M}$ concentration after 7-days and 28-days of curing. The slow dissolution of fly ash delayed the strength development of G50F50, but the abundance of sodium supplied by the higher concentration of $\mathrm{NaOH}$ at $16 \mathrm{M}$ molarity, led to formation of additional sodium-based silicate gel at the age of 90 days. This led to G50F50 surpassing the strength of G100 and G75F25, for this particular $\mathrm{NaOH}$ concentration.

Regardless of the $\mathrm{NaOH}$ concentration, the strength development rate for G50F50 is higher from the age of 28 days to the age of 90 days, compared to the rate from 7days to 28 days. This is particularly true for higher concentrations of $14 \mathrm{M}$ and $16 \mathrm{M}$ where the strength of G50F50, clearly approaches, then exceeds the strength of G75F25, as shown in Figure 7C,D. The higher alkalinity environment supports the continuity of fly ash dissolution with time, and the abundant supply of sodium to keep strength development continuing. 
A: $\mathrm{NaOH}$ Molarity $=10 \mathrm{M}$

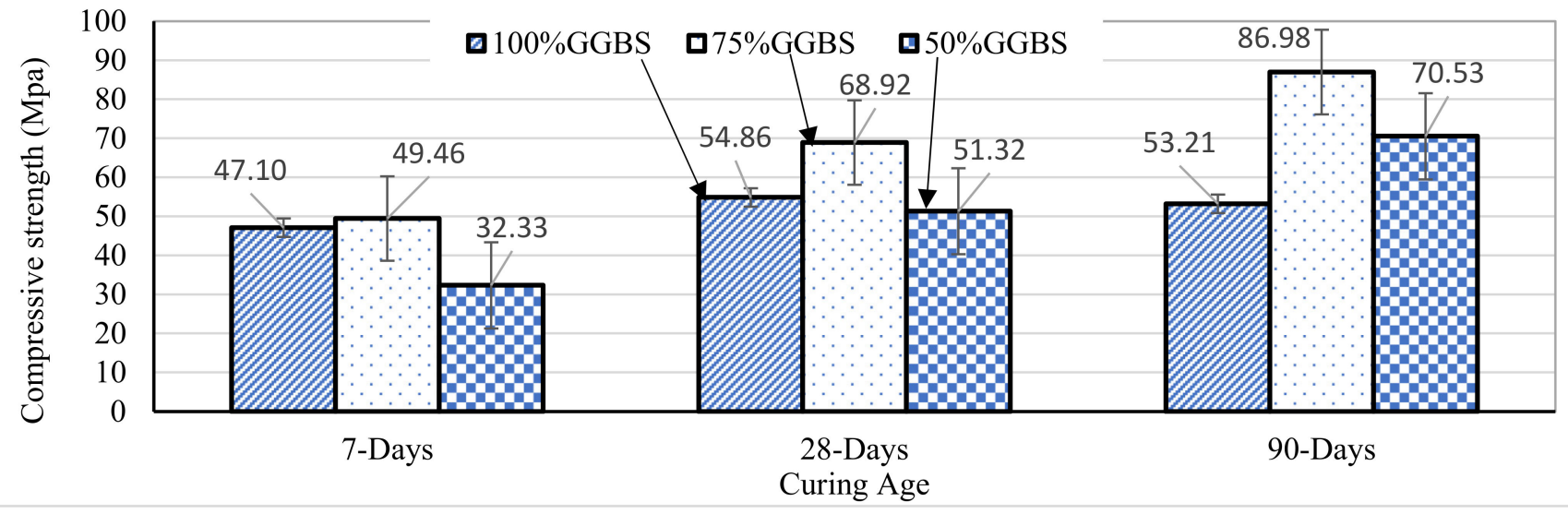

B: Molarity of $\mathrm{NaOH}=12 \mathrm{M}$

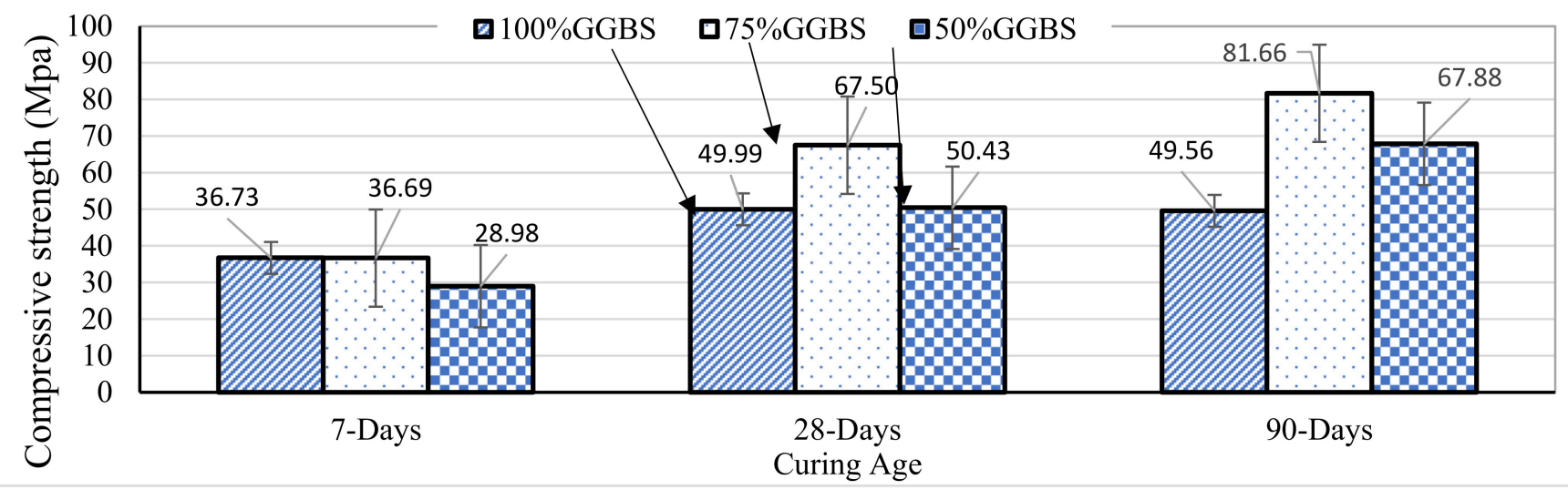

C: Molarity of $\mathrm{NaOH}=14 \mathrm{M}$

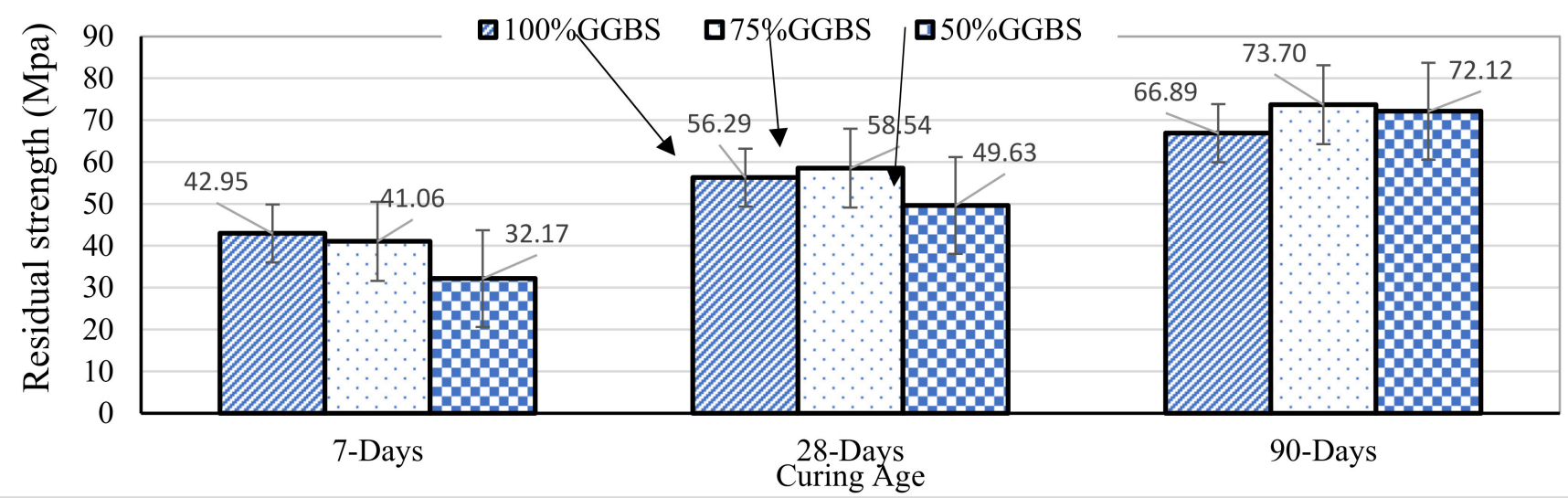

Figure 7. Cont. 


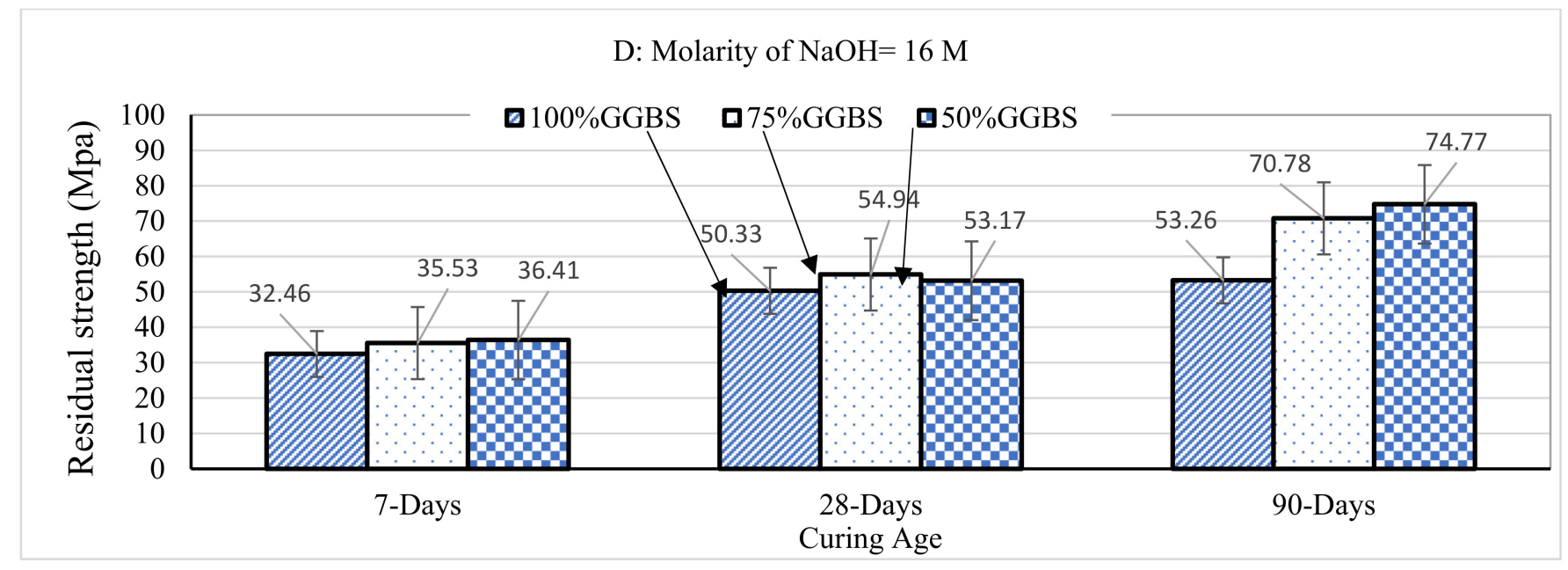

Figure 7. Compressive strength development for samples submerged under $10 \%$ sulfuric acid until compression test day. (A): Molarity of $\mathrm{NaOH}$ activator is $10 \mathrm{M},(\mathbf{B})$ : Molarity of $\mathrm{NaOH}$ activator is $12 \mathrm{M},(\mathbf{C})$ : Molarity of $\mathrm{NaOH}$ activator is $14 \mathrm{M}$, and (D): Molarity of $\mathrm{NaOH}$ activator is $16 \mathrm{M}$.

\section{Conclusions}

This study evaluated selected factors influencing sorptivity, setting time, and sulfuric acid resistance, of alkali-activated mortar samples in which the binder is either GGBS or combination or GGBS and fly ash. Effect of submersion in $10 \%$ sulfuric acid solution for up to 90 days on compressive strength development was also evaluated. These factors include the relative amounts of GGBS and fly ash in the binder, the ratio of sodium silicate-to-sodium hydroxide, and molarity of the sodium hydroxide alkaline activator. The findings apply to alkaline activator consisting of sodium silicate and sodium hydroxide with $\mathrm{Na}_{2} \mathrm{SiO}_{3} / \mathrm{NaOH}$ ranging from 1.5 to 2.5 . The concentration of the alkaline activator was adjusted by varying $\mathrm{NaOH}$ concentration from $10 \mathrm{M}$ to $16 \mathrm{M}$ in increments of $2 \mathrm{M}$. The following observations were made:

- Sorptivity decreases with curing age, regardless of the molarity of $\mathrm{NaOH}$ activator and regardless of the ratio of sodium silicate/sodium hydroxide. This pattern remains consistent for each binder composition, including 100\%GGBS, 75\%GGBS+25\% fly ash, and $50 \%$ GGBS $+50 \%$ fly ash. The optimum binder combination/activator mix, undergoing the lowest sorptivity and potentially enhancing durability, contains $75 \% \mathrm{GGBS}+25 \%$ fly ash with $\mathrm{NaOH}$ activator molarity of $12 \mathrm{M}$. The lowest sorptivity was exhibited by this combination after each of the three tested curing ages $(7,28$, and 90 days), compared to the other two binder combinations (100\%GGBS and 50\%GGBS+50\%fly ash). This indicates formation of hydration and polymerization products leading to filling of voids is optimum at this binder combination.

- For the mix with $100 \%$ GGBS binder, sorptivity tends to decrease with increase in the ratio of sodium silicate/sodium hydroxide, when $\mathrm{NaOH}=10 \mathrm{M}, 12 \mathrm{M}, 14 \mathrm{M}$, and $16 \mathrm{M}$. Samples prepared with binder combination 50\%GGBS+50\% fly ash experienced the lowest sorptivity after each curing age $(7,28$, and 90 days) when the activator ratio is 2.0 compared to samples prepared using activator ratios of 1.5 and 2.5 .

- Alkali-activated mortar samples prepared using alkali-activated GGBS/fly ash as binders did not experience visible damage nor mass loss when subjected to sulfuric acid for up to 90 days. To the contrary, mass of mortar samples increased after submersion in sulfuric acid for all GGBS/fly ash binder combinations. This is because the maximum fly ash content in the three binder combinations evaluated in this study was $50 \%$.

- Compressive strength of mortar samples submerged in 10\% sulfuric acid solution increased with age, for all binder combinations and all concentrations of $\mathrm{NaOH}$ activator. While sulfuric may have affected the matrix, hydration and polymerization 
products clearly supplemented and enhanced the pore system decreasing sorptivity and increasing compressive strength. The observation however, is limited to the curing in water for a maximum period of 90-days, and fly ash limit of 50\% of total binder content.

- Mortars with binder consisting of 75\%GGBS+25\% fly ash developed the highest compressive strength after 7-days, 28-days, and 90-days of curing, compared to 100\%GGBS and 50\%GGBS+50\%fly ash binder. This binder combination was also the optimum to produce minimum sorptivity in all curing ages. The optimum $\mathrm{NaOH}$ concentration for $75 \%$ GGBS+25\% fly ash binder to develop the highest 28-day compressive strength and lowest sorptivity is $12 \mathrm{M}$.

- The 50\%GGBS+50\% fly ash mix developed a high 90-day compressive strength of $86.74 \mathrm{MPa}$ when $\mathrm{NaOH}$ concentration was $16 \mathrm{M}$, corresponding to the highest solution alkalinity in this study.

- Initial and final setting times of mortar samples increase with molarity of $\mathrm{NaOH}$ when the binder is $100 \%$ GGBS and when the binder consists of $75 \%$ GGBS $+25 \%$ fly ash. Similarly, setting time of mortar samples increases with increase in fly ash content from $0 \%$ to $50 \%$.

Author Contributions: Conceptualization, O.A.M.; methodology, O.A.M. \& R.A.K.; validation, O.A.M. \& R.A.K. formal analysis, O.A.M. \& R.A.K.; resources, R.A.K.; data curation, R.A.K.; writingoriginal draft preparation, O.A.M.; writing—review and editing, R.A.K.; supervision, O.A.M.; project administration, O.A.M.; funding acquisition, O.A.M. All authors have read and agreed to the published version of the manuscript.

Funding: This research was funded by the Office of Research and Sponsored Programs at Abu Dhabi University, grant number 19300521 and grant number 19300460. The authors gratefully acknowledge the financial support through the ASPIRE Award for Research Excellence (AARE), Abu Dhabi, United Arab Emirates.

Data Availability Statement: All necessary data provided in the article.

Conflicts of Interest: The authors declare no conflict of interest.

\section{References}

1. Mohamed, O.A.; Rens, K.L.; Stalnaker, J.J. Time Effect of Alkali-Aggregate Reaction on Performance of Concrete. J. Mater. Civ. Eng. 2001, 13, 143-151. [CrossRef]

2. Mohamed, O.; Kewalramani, M.; Ati, M.; Al Hawat, W. Application of ANN for prediction of chloride penetration resistance and concrete compressive strength. Mater. 2021, 17, 101123. [CrossRef]

3. Mohamed, O.A.; Najm, O.F. Splitting tensile strength of self-consolidating concrete containing slag. In AES-ATEMA International Conference Series-Advances and Trends in Engineering Materials and Their Applications; AES ATEMA: Toronto, ON, Canada, 2016; pp. 109-114.

4. Mohamed, O.A.; Al Hawat, W. Influence of Fly Ash and Basalt Fibers on Strength and Chloride Penetration Resistance of Self-Consolidating Concrete. Mater. Sci. Forum 2016, 866, 3-8. [CrossRef]

5. Collins, F.; Sanjayan, J. Microcracking and strength development of alkali activated slag concrete. Cem. Concr. Compos. 2001, 23, 345-352. [CrossRef]

6. Zhang, S.P.; Zong, L. Evaluation of Relationship between Water Absorption and Durability of Concrete Materials. Adv. Mater. Sci. Eng. 2014, 2014, 650373. [CrossRef]

7. Mohamed, O.A. Effect of Mix Constituents and Curing Conditions on Compressive Strength of Sustainable Self-Consolidating Concrete. Sustainability 2019, 11, 2094. [CrossRef]

8. Provis, J.; Myers, R.; White, C.; Rose, V.; van Deventer, J.S. X-ray microtomography shows pore structure and tortuosity in alkali-activated binders. Cem. Concr. Res. 2012, 42, 855-864. [CrossRef]

9. Nedeljković, M.; Ghiassi, B.; van der Laan, S.; Li, Z.; Ye, G. Effect of curing conditions on the pore solution and carbonation resistance of alkali-activated fly ash and slag pastes. Cem. Concr. Res. 2019, 116, 146-158. [CrossRef]

10. Li, Q.; Yang, K.; Yang, C. An alternative admixture to reduce sorptivity of alkali-activated slag cement by optimising pore structure and introducing hydrophobic film. Cem. Concr. Compos. 2019, 95, 183-192. [CrossRef]

11. Mohamed, O.A. A Review of Durability and Strength Characteristics of Alkali-Activated Slag Concrete. Materials 2019, $12,1198$. [CrossRef] 
12. Parande, A.K.; Ramsamy, P.L.; Ethirajan, S.; Rao, C.R.K.; Palanisamy, N. Deterioration of reinforced concrete in sewer environments. In Proceedings of the Institution of Civil Engineers-Municipal Engineer; Thomas Telford Ltd: London, UK, 2006; Volume 159, pp. 11-20. [CrossRef]

13. Gutberlet, T.; Hilbig, H.; Beddoe, R. Acid attack on hydrated cement-Effect of mineral acids on the degradation process. Cem. Concr. Res. 2015, 74, 35-43. [CrossRef]

14. Fattuhi, N.; Hughes, B. The performance of cement paste and concrete subjected to sulphuric acid attack. Cem. Concr. Res. 1988, 18, 545-553. [CrossRef]

15. Ren, J.; Zhang, L.; Nicolas, R.S. Degradation of Alkali-Activated Slag and Fly Ash Mortars under Different Aggressive Acid Conditions. J. Mater. Civ. Eng. 2021, 33, 04021140. [CrossRef]

16. Zhang, W.; Yao, X.; Yang, T.; Zhang, Z. The degradation mechanisms of alkali-activated fly ash/slag blend cements exposed to sulphuric acid. Constr. Build. Mater. 2018, 186, 1177-1187. [CrossRef]

17. Siddique, S.; Jang, J.G. Acid and sulfate resistance of seawater based alkali activated fly ash: A sustainable and durable approach. Constr. Build. Mater. 2021, 281, 122601. [CrossRef]

18. Bakharev, T. Resistance of geopolymer materials to acid attack. Cem. Concr. Res. 2005, 35, 658-670. [CrossRef]

19. Gu, L.; Bennett, T.; Visintin, P. Sulphuric acid exposure of conventional concrete and alkali-activated concrete: Assessment of test methodologies. Constr. Build. Mater. 2019, 197, 681-692. [CrossRef]

20. Lee, N.; Lee, H. Influence of the slag content on the chloride and sulfuric acid resistances of alkali-activated fly ash/slag paste. Cem. Concr. Compos. 2016, 72, 168-179. [CrossRef]

21. Koenig, A.; Dehn, F. Main considerations for the determination and evaluation of the acid resistance of cementitious materials. Mater. Struct. 2015, 49, 1693-1703. [CrossRef]

22. Larreur-Cayol, S.; Bertron, A.; Escadeillas, G. Degradation of cement-based materials by various organic acids in agro-industrial waste-waters. Cem. Concr. Res. 2011, 41, 882-892. [CrossRef]

23. Aiken, T.A.; Kwasny, J.; Sha, W. Resistance of Alkali-Activated Binders to Organic Acids Found in Agri-Food Effluents. J. Mater. Civ. Eng. 2021, 33, 04021024. [CrossRef]

24. Dehghani, A.; Aslani, F.; Panah, N.G. Effect of initial SiO2/Al2O3 molar ratio and slag on fly ash-based ambient cured geopol-ymer properties. Constr. Build. Mater. 2021, 293, 123527. [CrossRef]

25. Jang, J.; Lee, N.; Lee, H. Fresh and hardened properties of alkali-activated fly ash/slag pastes with superplasticizers. Constr. Build. Mater. 2014, 50, 169-176. [CrossRef]

26. Wardhono, A.; Law, D.W.; Strano, A. The strength of alkali-activated slag/fly ash mortar blends at ambient temperature. Proceda Eng. 2015, 125, 650-656. [CrossRef]

27. Gao, X.; Yu, Q.; Brouwers, H. Characterization of alkali activated slag-fly ash blends containing nano-silica. Constr. Build. Mater. 2015, 98, 397-406. [CrossRef]

28. Ismail, I.; Bernal, S.A.; Provis, J.; Nicolas, R.S.; Brice, D.G.; Kilcullen, A.R.; Hamdan, S.; van Deventer, J.S. Influence of fly ash on the water and chloride permeability of alkali-activated slag mortars and concretes. Constr. Build. Mater. 2013, 48, $1187-1201$. [CrossRef]

29. Uppalapati, S.; Vandewalle, L.; Özlem, C. Autogenous shrinkage of slag-fly ash blends activated with hybrid sodium silicate and sodium sulfate at different curing temperatures. Constr. Build. Mater. 2020, 265, 121276. [CrossRef]

30. Lee, N.; Jang, J.; Lee, H. Shrinkage characteristics of alkali-activated fly ash/slag paste and mortar at early ages. Cem. Concr. Compos. 2014, 53, 239-248. [CrossRef]

31. Mohamed, O.; Najm, O. Effect of Curing Methods on Compressive Strength of Sustainable Self-Consolidated Concrete. IOP Conf Series: Mater. Sci. Eng. 2019, 471, 032059. [CrossRef]

32. ASTM C618-19; Standard Specification for Coal Fly Ash and Raw or Calcined Natural Pozzolan for Use in Concrete. ASTM International: West Conshohocken, PA, USA, 2019. Available online: www.astm.org (accessed on 26 January 2022).

33. Hall, C. Water sorptivity of mortars and concretes: A review. Mag. Concr. Res. 1989, 41, 51-61. [CrossRef]

34. ASTM C1585-20; Standard Test Method for Measurement of Rate of Absorption of Water by Hydraulic Cement Concretes. ASTM International: West Conshohocken, PA, USA, 2020. Available online: www.astm.org (accessed on 26 January 2022).

35. Bernal, S.A.; Provis, J.L. Durability of Alkali-Activated Materials: Progress and Perspectives. J. Am. Ceram. Soc. 2014, 97, 997-1008. [CrossRef]

36. Duxson, P.; Provis, J.L.; Lukey, G.C.; Mallicoat, S.W.; Kriven, W.M.; van Deventer, J.S.J. Understanding the relationship between geopolymer composition, microstructure and mechanical properties. Colloids Surf. A Physicochem. Eng. Asp. 2005, 269, 47-58. [CrossRef]

37. ASTM C267-20; Standard Test Methods for Chemical Resistance of Mortars, Grouts, and Monolithic Surfacings and Polymer Concretes. ASTM International: West Conshohocken, PA, USA, 2020. Available online: www.astm.org (accessed on 26 January 2022).

38. Hu, X.; Shi, C.; Shi, Z.Z.; Zhang, L. Compressive strength, pore structure and chloride transport properties of alkali-activated slag/fly ash mortars. Cem. Concr. Compos. 2019, 104, 103392. [CrossRef]

39. Mehta, A.; Siddique, R.; Ozbakkaloglu, T.; Shaikh, F.A.; Belarbi, R. Fly ash and ground granulated blast furnace slag-based al-kali-activated concrete: Mechanical, transport and microstructural properties. Constr. Build. Mater. 2020, 257, 119548. [CrossRef] 
40. Hooton, R.D.; Nokken, M.R. Dependence of Rate of Absorption on Degree of Saturation of Concrete. Cem. Concr. Aggregates 2002, 24, 20-24. [CrossRef]

41. Mohamed, O. Durability and Compressive Strength of High Cement Replacement Ratio Self-Consolidating Concrete. Buildings 2018, 8, 153. [CrossRef]

42. Shah, S.F.A.; Chen, B.; Oderji, S.Y.; Haque, M.A.; Ahmad, M.R. Improvement of early strength of fly ash-slag based one-part alkali activated mortar. Constr. Build. Mater. 2020, 246, 118533. [CrossRef]

43. Lee, N.K.; Lee, H.K. Setting and mechanical properties of alkali-activated fly ash/slag concrete manufactured at room temperature. Constr. Build. Mater. 2013, 47, 1201-1209. [CrossRef] 